\title{
Indirect lung injury predictive model in experimental trauma
}

\author{
${ }^{{ }_{1}, 2}$ Oleg Arnaut, ${ }^{2}$ Ion Grabovschi, ${ }^{2}$ Serghei Sandru, \\ ${ }^{3}$ Gheorghe Rojnoveanu, ${ }^{1}$ Ruslan Baltaga
}

\author{
${ }^{1}$ Department of Human Physiology and Biophysics, ${ }^{2}$ Valeriu Ghereg Department of Anesthesiology and Intensive Care \\ ${ }^{3}$ Nicolae Anestiadi Department of Surgery, Nicolae Testemitanu State University of Medicine and Pharmacy \\ Chisinau, the Republic of Moldova
}

\author{
Authors' ORCID iDs, academic degrees and contributions are available at the end of the article \\ *Corresponding author: oleg.arnaut@usmf.md \\ Manuscript received January 31, 2021; revised manuscript April 02, 2021; published online April 28, 2021
}

\begin{abstract}
Background: Trauma remains a medical-social problem, still having high lethality rate. Indirect lung injury (ILI) occurs in trauma due to systemic neutrophils activation and proteases release into primarily intact tissues. There are no data in the literature regarding ILI predictive models in trauma. Material and methods: In the experimental study (19 traumatized male rabbits), the proteases, antiproteases and the pulmonary morphological changes, assessed according to the SAMCRS score (Semiquantitative Reflected Qualitative Changes Assessment Scale) were followed. There were used two statistical instruments - correlational analysis and multivariate linear regression.

Results: Initially, a correlational analysis between the values of the SAMCRS score and the proteases/ anti proteases was performed. The null hypothesis was rejected $(\mathrm{F}=7.017, \mathrm{p}=.002)$. The correlation coefficient of the predicted results and the real values of SAMCRS coefficient being .626. The final model included the following parameters: constant (B = 9.427; 95\% CI 7.341, 11.513; p <.001); $\alpha 2$-macroglobulin 0 $(\mathrm{B}=-4.053 ; 95 \% \mathrm{Cl}-6.350,-1.757 ; \mathrm{p}=.002) ; \mathrm{AEAMP}_{0}(\mathrm{~B}=.002 ; 95 \% \mathrm{CI} .000, .004 ; \mathrm{p}=.075) ; \mathrm{AEAMP}_{24}(\mathrm{~B}=-.006 ; 95 \% \mathrm{CI}-.010,-.002 ; \mathrm{p}=.003) ; \mathrm{AECG}_{2}$ $(\mathrm{B}=.081 ; 95 \% \mathrm{CI} .040, .122 ; \mathrm{p}=.001) ; \mathrm{AEE}_{0}(\mathrm{~B}=-.026 ; 95 \% \mathrm{CI}-.040,-.011 ; \mathrm{p}=.002)$.

Conclusions: In this research, a predictive model for indirect lung injury in experimental trauma was developed, the predictors being some elements of the proteases/antiproteases system. This, in turn, allows the hypotheses emission regarding the pathophysiology, prophylaxis and treatment of ILI. Key words: trauma, indirect lung injury, predictive model.
\end{abstract}

\section{Cite this article}

Arnaut O, Grabovschi I, Sandru S, Rojnoveanu G, Baltaga R. Indirect lung injury predictive model in experimental trauma. Mold Med J. 2021;64(2): 21-25. https://doi.org/10.52418/moldovan-med-j.64-2.21.04.

\section{Introduction}

The epidemiological data in the Republic of Moldova regarding the trauma showed alarming numbers, traumatic injuries being the first cause of death in the age group of 1-44 years [1]. The principal causes of "traumatic death" are severe trauma and polytrauma. They are characterized by a series of systemic mechanisms activation with pro-/anticoagulant, pro-/antiinflammatory, endocrine, nervous and immune systems enrolment in order to restore/maintain the homeostasis [2].

Thus, in conditions of traumatic injuries, it's important to consider both, the lesion severity and the host response. Under normal conditions, the aseptic inflammation, generated by trauma, remains local. Polytrauma or severe trauma amplifies the process and Systemic Inflammatory Response Syndrome (SIRS) occurs. As a result, the immune cells, forming inflammasomes, are activated via cytokines and chemokines, vascular permeability being increased via expression of adhesins in the surrounding endothelium. This, in turn, allows the immunocompetent cell accumulation besides injured tissues in healthy, normal tissues with following degranulation at this site. Consequently, some ag- gressive agents, as reactive oxygen species (ROS) and proteases, determine the lesions in the tissues that are far from the primary traumatic lesions. As named "indirect" injuries, decreasing the functional reserves with organs failure (sometimes multiple organ failure (MOF)) appearance are an unresolved problem in critical care patients management [3].

Literature has described "indirect" injuries in different organs: central nervous system/brain and spinal column - disruption of the blood-brain and blood-spinal barriers, heart - acute coronary syndrome, liver - acute hepatic injuries, kidney - acute kidney injuries, endothelium of systemic vessels - disseminated intravascular coagulation etc. [4-7]. Indirect lung injury (ILI or indirect ARDS (Acute Respiratory Distress Syndrome)) represents the most common type of "indirect" injuries, explanation being neutrophils rapid accumulation (minutes, hours) in the interstitial space and bronchoalveolar fluid of the lungs after the trigger factors influence. This can be explained by some pulmonary microcirculatory bed particularities, neutrophils redistribution before trigger factor actioning, their passage through alveolocapillary barrier and late apoptosis. Compared with 
other organs where cells can concentrate in the postcapillary venules, in the lungs, they will cumulate in the capillaries themselves that are connected in a short segment network. This will increase about 50 times the capillary walls exposure period to neutrophils compared to other body areas [8]. Existing therapies, especially synthetic antiproteases administration, did not show efficiency in order to decrease the mortality rate - data from randomized clinical trial [9] and meta-analysis from 2017 [10].

Taking into account the information above ILI needs additional researches. The study aim was indirect post-traumatic lung injury predictive model elaboration for hypotheses emission regarding the pathophysiological mechanisms, prophylaxis and potential therapies of ILI.

\section{Material and methods}

In the experimental study were used 19 severely traumatized rabbits according to the method described above [11]. The proteases, antiproteases and the pulmonary morphological changes, assessed according to the Semiquantitative Reflected Qualitative Changes Assessment Scale (SAMCRS), were analyzed.

Protease/antiprotease system components were used as biomarkers/predictors of "indirect" lesions and lung functional state at 24 hours after trauma. From collected and frozen samples, later, Elastase (AEE), Cathepsins $G$ (AECG), D (AECD), L (AECL), H (AECH), Trypsin (AET), Adenosinedesaminase (AEADA) and Adenilatdesaminase (AEAMP) enzymatic activity, the same as á2-macroglobulin and á1-antitrypsin was measured before, at 2, 5 and 24 hours after the trauma, using spectrophotometry method.

Collected tissue samples analysis was used as an instrument for "indirect" lesion quantification. Initially, the collected samples followed the hematoxylin eosin coloration technique: fixation, washing, dehydration, waxing, sectioning, etalation, dewaxing, hydration, coloration and mounting. Morphological pieces examination was performed using artificial light optical microscope ("Micros", Austria) using objectives needed for an optimal amplifi-

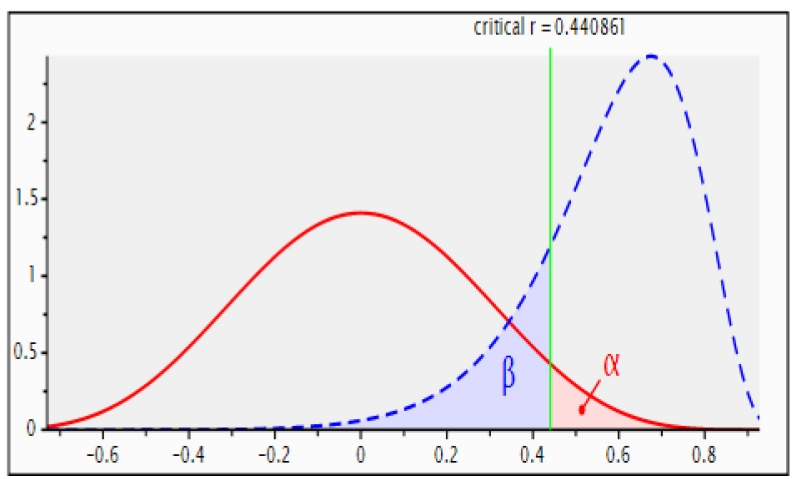

cation (x100 or x200 each time) of the studied structures. Histological samples were evaluated from 0 to 3 based on SAMCRS as follows: 0 - no any notable changes, 1 - weak changes, 2 - moderate changes, 3 - excessive changes. SIRS characteristics where analyzed for every tissue. Interstitial edema, venous congestion, interstitial granulocyte infiltration, hemorrhagic impregnation, lung hemosiderosis were attested. SAMCRS lungs $_{\text {S }}$ score was appreciated by summing all the intensities of the listed above changes observed in the lungs [11].

There were used two statistical instruments - correlational analysis (Spearman $\rho$ test) with effect size estimation and multivariate linear regression. Initially, by building a histogram (extremes identification) and by distribution analysis (Shaporo test) of the measured biochemical and histological parameters, they were identified and where needed, normalized (by logarithmic function), the data was prepared for identification of the potential biomarkers/predictors of the "indirect" lung injury. Using the Spearman $\rho$ test there were identified the associations $(\mathrm{p}<.05)$ or tendencies to associate $(\mathrm{p}<.1)$ of the protease/antiprotease system components with SAMCRS for ILI. At the same time, there were analyzed the associations between different proteases/ antiproteases system components in order to identify the potential sources for multicollinearity as an obstacle for predictive models' elaboration.

Minimal sample size was estimated by using version 3.1.9 GPower software [12]. Left side of the figure shows the distribution plot estimating correlation coefficient critical value. On the right side are listed the parameters needed for sample size estimation (fig. 1). Calculated minimal number of the statistical units was 15 (power $0.8, \alpha=0.05$, expected $\rho$ value being 0.6 , using unilateral hypotheses).

Having 19 statistical units, we can consider a sufficient research power. Finally, was elaborated a predictive model for "indirect" lung injury in the experimental severe trauma. The applied statistical method to elaborate the models able to predict the "indirect" lesion severity was the linear regression (backward method) used according to the standards recommended by the literature sources [13].

Fig. 1. Distribution with critical $\mathbf{r}$ (left) and sample size estimation (right) 
Table 1. Linear regression coefficients and collinearity analysis for SAMCRS $_{\text {lungs }}$ values prediction in experimental severe trauma

\begin{tabular}{|c|c|c|c|c|c|c|c|c|c|}
\hline & \multicolumn{2}{|c|}{$\begin{array}{l}\text { Unstandardized } \\
\text { Coefficients }\end{array}$} & \multirow{2}{*}{$\begin{array}{c}\text { Standardized } \\
\text { Coefficients } \\
\text { Beta }\end{array}$} & \multirow{2}{*}{$\mathbf{t}$} & \multirow{2}{*}{ Sig. } & \multicolumn{2}{|c|}{$\begin{array}{l}95.0 \% \text { Confidence } \\
\text { Interval for B }\end{array}$} & \multicolumn{2}{|c|}{ Collinearity Statistics } \\
\hline & B & $\begin{array}{l}\text { Std. Er- } \\
\text { ror }\end{array}$ & & & & $\begin{array}{l}\text { Lower } \\
\text { Bound }\end{array}$ & $\begin{array}{l}\text { Upper } \\
\text { Bound }\end{array}$ & Tolerance & VIF \\
\hline (Constant) & 9.427 & .966 & & 9.763 & .000 & 7.341 & 11.513 & & \\
\hline$a_{2}$-macroglobulin 0 & -4.053 & 1.063 & -.847 & -3.813 & .002 & -6.350 & -1.757 & .421 & 2.373 \\
\hline AEAMP $_{0}$ & .002 & .001 & .430 & 1.937 & .075 & .000 & .004 & .423 & 2.366 \\
\hline AEAMP $_{24}$ & -.006 & .002 & -1.353 & -3.569 & .003 & -.010 & -.002 & .145 & 6.905 \\
\hline AECG $_{2}$ & .081 & .019 & 1.089 & 4.306 & .001 & .040 & .122 & .325 & 3.076 \\
\hline AEE $_{0}$ & -.026 & .007 & -.698 & -3.840 & .002 & -.040 & -.011 & .630 & 1.588 \\
\hline
\end{tabular}

Note: Std. Error -standard error for B coefficient, $t$ - t test, Sig. - significance, VIF - variance inflation factor, $\alpha_{2}-m_{a c r o g l o b u l i n}-\alpha_{2}-m_{a c r o g l o b u l i n e n z y m a t i c}$ activity before trauma, AEAMP ${ }_{0}$ - Adenosinedesaminase before trauma, AEAMP 24 - Adenosinedesaminase measured at 24 hours after trauma, AECG Cathepsin $G$ enzymatic activity measured at 2 hours after trauma, AEE - Elastase enzymatic activity measured before the trauma

\section{Results}

Correlation analysis showed the following correlations $(\mathrm{p}<.05)$ or tendencies for correlations $(\mathrm{p}<.1)$. SAMCRS was associated with $\mathrm{AET}_{0}(\mathrm{r}=-.343, \mathrm{p}=.075$, effect size $.12), \mathrm{AET}_{2}\left(\mathrm{r}=.466, \mathrm{p}=.022\right.$, effect size .22), $\mathrm{AET}_{24}$ ( $\mathrm{r}=-$ $.358, \mathrm{p}=.066$, effect size .13$), \mathrm{a}_{2}$-macroglobuline m $_{2}(\mathrm{r}=-.401$, $\mathrm{p}=.044$, effect size .16), AEAMP $_{24}(\mathrm{r}=.311, \mathrm{p}=.097$, effect size .01), $\mathrm{AECG}_{2}\left(=.590, \mathrm{p}=.004\right.$, effect size .35), $\mathrm{AECG}_{24}$ $(\mathrm{r}=-.317, \mathrm{p}=.093$, effect size .10$), \mathrm{AECL}_{2}(\mathrm{r}=.441, \mathrm{p}=.029$, effect size .20), $\operatorname{AEE}_{0}(\mathrm{r}=-.479, \mathrm{p}=.019$, effect size .23$), \mathrm{AEE}_{24}$ ( $\mathrm{r}=-.342, \mathrm{p}=.076$, effect size .17$)$. These potential biomarkers were used for ILI prediction. Also, because of possible predisposition for ILI, were considered the initial values, before the trauma.

Predictive model for SAMCRS lungs $_{\text {was }}$ elaborated using backward technique. The final model correlation coefficient between predicted histological modifications and

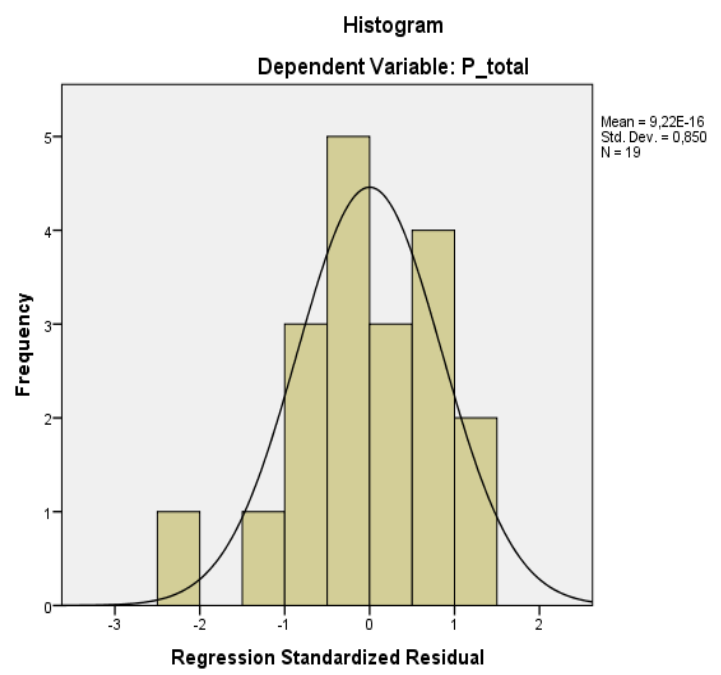

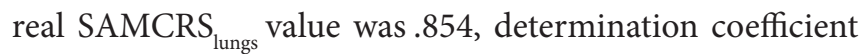
equal to .626, the sum of squares being 17896 from 24526 possible. The null hypothesis (there are no parameters with predictive potential for SAMCRS ${ }_{\text {lungs }}$ values at 24 hours after experimental trauma) was rejected $(\mathrm{F}=7.017, \mathrm{p}=.002)$.

The final model included the following parameters (tab. 1):

- Constant ( $\mathrm{B}=9.427 ; 95 \% \mathrm{CI} 7.341,11.513 ; \mathrm{p}<.001)$;

- $\alpha_{2}$-macroglobulin $(B=-4.053 ; 95 \% C I-6.350,-1.757$; $\mathrm{p}=.002)$;

- $\operatorname{AEAMP}_{0}(\mathrm{~B}=.002 ; 95 \% \mathrm{CI} .000, .004 ; \mathrm{p}=.075)$;

- $\mathrm{AEAMP}_{24}(\mathrm{~B}=-.006 ; 95 \% \mathrm{CI}-.010,-.002 ; \mathrm{p}=.003)$;

- $\mathrm{AECG}_{2}(\mathrm{~B}=.081 ; 95 \% \mathrm{CI} .040, .122 ; \mathrm{p}=.001)$;

- $\mathrm{AEE}_{0}(\mathrm{~B}=-.026 ; 95 \% \mathrm{CI}-.040,-.011 ; \mathrm{p}=.002)$.

Other potential biomarkers like $\mathrm{AET}_{0}, \mathrm{AET}_{2}, \mathrm{AET}_{24}$, $\mathrm{AECG}_{24}, \mathrm{AECL}_{2}, \mathrm{AEE}_{24}$ the same as for their value before the trauma were not significative, thus, they weren't included in the final model of "indirect" lung lesions prediction. The

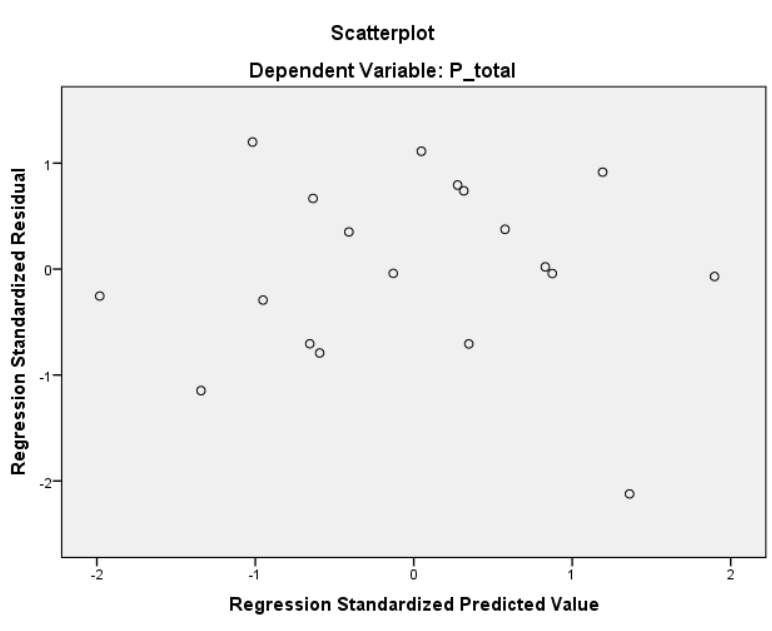

Fig. 2. Standardized residual distribution (left) and scatterplot of the standardized predictive values and standardized residuals (right) 
obtained model has the following mathematical expression (Equation 1):

SAMCRS $_{\text {lungs }}$ at 24 hours $=9.427-a_{2}$ - macroglobulin $_{0} *$ $4.053+\operatorname{AEAMP}_{0}{ }^{*} .002-\mathrm{AEAMP}_{24}{ }^{*} .006+\mathrm{AECG}_{2}{ }^{*}$ $.081-\mathrm{AEE}_{0} * .026$ (Equation 1)

As the analysis of collinearity showed, the quality of the prediction is not affected by the potential strong correlations between the parameters included in the model (Tolerance and VIF being more than 0.1 and less than 10 respectively). From a quantitative point of view, it has been demonstrated by standardizing the coefficients that the effects of

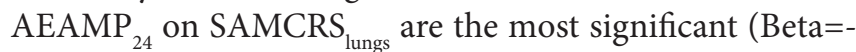
1.353), followed by $\mathrm{AECG}_{2}$ (Beta=1.089), $\alpha_{2}$-macroglobulin $($ Beta $=-.847), \mathrm{AEE}_{0}($ Beta $=-.698)$ and $\mathrm{AEAMP}_{0}($ Beta $=.430)$.

In addition, the developed model also met the necessary conditions for residual linear regression. Their analysis demonstrated an almost normal distribution and lack of associations between standardized predictive values and standardized residuals (fig. 2). All these together allow us to consider the model as a suitable one.

Considering that the model was developed on a relatively small number of participants, which increases the risk of model instability, especially since the latter included five biomarkers in addition to the constant, resampling was performed by bootstrapping (tab. 2). The model has shown its stability, $\mathrm{AECG}_{2}, \mathrm{AEAMP}_{0}$ and a2-macroglobulin being $_{0}$ potential biomarkers for distant lung damage. The effects of $\mathrm{AEAMP}_{24}$ and $\mathrm{AEE}_{0}$, even if significant and stable, require verification in subsequent studies.

\section{Discussion}

In severe trauma or polytrauma through cytokine storm immunocompetent cells are activated, infiltrate intact tissues and produces "indirect" lesions [14]. Actual research had the aim to probe the proteases/antiproteases components, deposited in neutrophils and other immunocompetent cells, as predictors for posttraumatic ILI by histological modification modeling. Obtained information, in perspective, will complete the knowledge in this field.

In general, elaborated model showed acceptable characteristics with no multicollinearity, no residuals problem and stability, according to linear regression procedure [13]. The model included both, proteases and antiproteases, each of them having protective or destructive potential. The concept of the antiproteases protective effects and the proteases destructive effects in our research is supported by the signs in front of the regression coefficients of a2-macroglobulin, $\mathrm{AEAMP}_{0}$ and $\mathrm{AECG}_{2}$. a2-macroglobulin (macromolecular antiprotease) is a plasma glycoprotein best known for its ability to inhibit a broad spectrum of serine, threonine, and metalloproteases as well as inflammatory cytokines [15]. Cathepsin $\mathrm{G}$ activates coagulation, having immunostimulatory and antimicrobial effects or it can increase vascular permeability promoting edema. Also, it increases metalloproteinase activity with further vascular matrix destruction [16-18]. Because AEAMP 24 and $\mathrm{AEE}_{0}$ are proteases, the negative signs in front of the regression coefficients can suggest some suspect results. Possibly, this fact can be explained by the need to complete the model ( $1 / 3$ of the dispersion is not explained, the constant being significant), their adjustment to the potential effective variables will reverse their sign or will exclude them from the final model. Other possible variants - the proteases are balanced by antiproteases before the trauma or they have protective effects in case of pulmonary lesions. The model took into account the predictor's value before the trauma ( $\alpha_{2}$-macroglobulin , AEAMP $_{0}, \mathrm{AEE}_{0}$ ). There are some opinions that it can show a predisposition for ILI in conditions of severe trauma.

At the same time, the elaborated model has some limitations. First, the model needs to be improved by adding some effective parameters/variables up to $.80(80 \%)$ value of the determination coefficient to remove one of the research's imperfections, namely that about one third of the SAMCRS at 24 hours after trauma dispersion remains unexplained. Second, the activated neutrophils ROS releases besides proteases, that were not investigated and, probably, could improve the model [3]. Third, the confidence intervals range needs precision. Fourth, the research is experimental one, model being male rabbits - the argument to validate or adapt the model for human being. At the same time, similar research in clinical practice could be performed only by changing the design.

Table 2. Resampling by bootstrapping. SAMCRS ${ }_{\text {lungs }}$ predictive model at 24 hours after trauma

\begin{tabular}{|c|c|c|c|c|c|c|}
\hline & \multirow{2}{*}{ B } & \multirow{2}{*}{ Bias } & \multirow{2}{*}{ Std. Error } & \multirow{2}{*}{ Sig. (2-tailed) } & \multicolumn{2}{|c|}{ 95\% Confidence Interval } \\
\hline & & & & & Lower & Upper \\
\hline (Constant) & 9.427 & .047 & 1.369 & .001 & 6.683 & 12.193 \\
\hline $\mathrm{AECG}_{2}$ & .081 & -.003 & .026 & .009 & .022 & .129 \\
\hline AEAMP $_{0}$ & .002 & $3.004 \mathrm{E}-05$ & .001 & .079 & .000 & .005 \\
\hline AEAMP $_{24}$ & -.006 & .000 & .002 & .016 & -.011 & -.002 \\
\hline $\mathrm{AEE}_{0}$ & -.026 & .000 & .008 & .011 & -.039 & -.009 \\
\hline$a_{2}-$ macroglobulin $_{0}$ & -4.053 & -.166 & 1.514 & .039 & $\mid-7.364$ & -1.264 \\
\hline
\end{tabular}

Note: Std. Error - standard error for B coefficient, Sig. - significance, AECG $_{2}$ - Cathepsin G enzymatic activity measured at 2 hours after trauma,

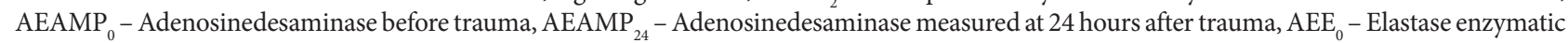
activity measured before the trauma, $\alpha_{2}$ - macroglobulin $_{0}-\alpha_{2}$-macroglobulin enzymatic activity before trauma. 


\section{Conclusions}

In the current research, a predictive model for indirect lung injury in experimental trauma was developed. This, in turn, allows the hypotheses emission regarding the pathophysiology, prophylaxis and treatment of post-traumatic ILI. The model needs validation/adaptation in clinical research.

Three predictors are represented by the proteases/antiproteases system components before the trauma, two proteases $\left(\mathrm{AEAMP}_{0}, \mathrm{AEE}_{0}\right)$ and antiprotease $\alpha_{2}$-macroglobulin . $^{\text {. }}$ This can suggest a predisposition of some individuals for developing a post-traumatic ILI.

\section{References}

1. Arnaut O, Croitoru D, Grabovschi I, Sandru S. Trauma scoring systems. Mold Med J. 2020;63(1):64-74. doi: 10.5281/ZENODO.3685673.

2. Lord JM, Midwinter MJ, Chen YF, Belli A, Brohi K, Kovacs EJ, Koenderman L, Kubes P LR. The systemic immune response to trauma: an overview of pathophysiology and treatment. Lancet. 2014;384(9952):14551465. doi: 10.1016/S0140-6736(14)60687-5.

3. Osuka A, Ogura H, Ueyama M, Shimazu T, Lederer JA. Immune response to traumatic injury: harmony and discordance of immune system homeostasis. Acute Med Surg. 2014;1(2):63-69. doi: 10.1002/ams2.17.4. Kipnis E. Inflammasomes in tissue damages and immune disorders after trauma. Front Immunol. 2018;9:1-17. doi: 10.3389/fimmu.2018.01900.

5. Gando S, Otomo Y. Local hemostasis, immunothrombosis, and systemic disseminated intravascular coagulation in trauma and traumatic shock. Crit Care. 2015;19(1):1-11. doi:10.1186/s13054-015-0735-x.

6. Lai WH, Rau CS, Wu SC, et al. Post-traumatic acute kidney injury: A cross-sectional study of trauma patients. Scand J Trauma Resusc Emerg Med. 2016;24(1):1-7. doi: 10.1186/s13049-016-0330-4.

7. Ramaiah SK, Jaeschke H. Role of neutrophils in the pathogenesis of acute inflammatory. Toxicol Patol. 2007;35(6):757-766. doi: $10.1080 / 01926230701584163$
8. Burns AR, Smith CW, Walker DC. Unique structural features that influence neutrophil emigration into the lung. Physiol Rev. 2003;83(2):309336. doi: 10.1152/physrev.00023.2002.

9. Zeiher BG, Artigas A, Vincent J-L, et al. Neutrophil elastase inhibition in acute lung injury: results of the STRIVE study. Crit Care Med. 2004;32(8):1695-1702. doi: 10.1097/01.ccm.0000133332.48386.85.

10. Pu S, Wang D, Liu D, et al. Effect of sivelestat sodium in patients with acute lung injury or acute respiratory distress syndrome: A meta-analysis of randomized controlled trials. BMC Pulm Med. 2017;17(1):1-9. doi 10.1186/s12890-017-0498-z.

11. Arnaut O, Munteanu A, Grabovschi I, et al. Modelul animal de ALI/ ARDS cauzat de politraumatism [Animal model of ALI/ARDS caused by polytrauma]. Arch Balkan Med Union. 2012;47(Suppl 4):126-132. Romanian.

12. Faul F, Erdfelder E, Lang AG, Buchner A. G*Power 3: a flexible statistical power analysis program for the social, behavioral, and biomedical sciences. Behav Res Methods. 2007;39(2):175-191. doi: 10.3758/ BF03193146.

13. Marill KA. Advanced statistics: linear regression, part II: multiple linear regression. Acad Emerg Med. 2004;11(1):94-102. doi: 10.1197/j. aem.2003.09.006.

14. Leliefeld PHC, Wessels CM, Leenen LPH, Koenderman L, Pillay J. The role of neutrophils in immune dysfunction during severe inflammation. Crit Care. 2016;20:73. doi: 10.1186/s13054-016-1250-4.

15. Cuéllar JM, Cuéllar VG, Scuderi GJ. a(2)-Macroglobulin: Autologous Protease Inhibition Technology. Phys Med Rehabil Clin N Am. 2016;27(4):909-918. doi: 10.1016/j.pmr.2016.06.008.

16. Gale AJ, Rozenshteyn D. Cathepsin G, a leukocyte protease, activates coagulation factor VIII. Thromb Haemost. 2008;99(1):44-51. doi: 10.1160/ TH07-08-0495.

17. Faraday N, Schunke K, Saleem S, et al. Cathepsin G-dependent modulation of platelet thrombus formation in vivo by blood neutrophils. PLoS One. 2013;8(8):e71447. doi: 10.1371/journal.pone.0071447.

18. Gao S, Zhu H, Zuo X, Luo H. Cathepsin g and its role in inflammation and autoimmune diseases. Arch Rheumatol. 2018;33(4):748-749. doi: 10.5606/ArchRheumatol.2018.6595.

\author{
Authors' ORCID iDs and academic degrees \\ Oleg Arnaut, MD, PhD, Associate Professor - https://orcid.org/0000-0002-5483-8672 \\ Ion Grabovschi, MD, Assistant Professor - https://orcid.org/0000-0002-7716-9926 \\ Serghei Sandru, MD, PhD, Professor - https://orcid.org/0000-0002-2973-9154 \\ Gheorghe Rojnoveanu, MD, PhD, Professor - https://orcid.org/0000-0001-7075-4113 \\ Ruslan Baltaga, MD, PhD, Associate Professor - https://orcid.org/0000-0003-0659-4877
}

\title{
Authors' contributions
}

OA designed the trial and interpreted the data. IG and RB interpreted the data. SS and GR revised the manuscript critically. All the authors approved the final version of the manuscript.

\section{Funding}

This study was supported by Nicolae Testemitanu State University of Medicine and Pharmacy. The trial was the authors' initiative. The authors are independent and take responsibility for the integrity of the data and accuracy of the data analysis.

\section{Ethics approval and consent to participate}

The research project was approved by the Research Ethics Committee of Nicolae Testemitanu State University of Medicine and Pharmacy (Protocol No 46, 16.12.2016).

\section{Conflict of Interests}

No competing interests were disclosed. 